Article

\title{
Solid-State Transformers: Fundamentals, Topologies, Applications, and Future Challenges
}

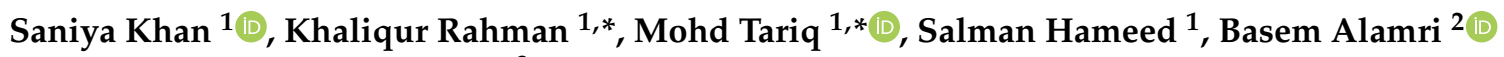 \\ and Thanikanti Sudhakar Babu ${ }^{3}$ \\ 1 Department of Electrical Engineering, ZHCET, Aligarh Muslim University, Aligarh 202002, India; \\ saniyakhan3720@gmail.com (S.K.); hameeddee@gmail.com (S.H.) \\ 2 Department of Electrical Engineering, College of Engineering, Taif University, Taif 21944, Saudi Arabia; \\ b.alamri@tu.edu.sa \\ 3 Department of Electrical and Electronics Engineering, Chaitanya Bharathi Institute of Technology, \\ Hyderabad 500075, India; sudhakarbabu@ieee.org \\ * Correspondence: k.rahmaneed@gmail.com (K.R.); tariq.ee@zhcet.ac.in (M.T.)
}

Citation: Khan, S.; Rahman, K.;

Tariq, M.; Hameed, S.; Alamri, B.;

Babu, T.S. Solid-State Transformers:

Fundamentals, Topologies,

Applications, and Future Challenges. Sustainability 2021, 14, 319. https:// doi.org/10.3390/su14010319

Academic Editor: Armando Cartenì

Received: 9 September 2021

Accepted: 9 November 2021

Published: 29 December 2021

Publisher's Note: MDPI stays neutral with regard to jurisdictional claims in published maps and institutional affiliations.

Copyright: (c) 2021 by the authors. Licensee MDPI, Basel, Switzerland. This article is an open access article distributed under the terms and conditions of the Creative Commons Attribution (CC BY) license (https:// creativecommons.org/licenses/by/ $4.0 /)$.

\begin{abstract}
Solid-state transformers (SSTs) have emerged as a superior alternative to conventional transformers and are regarded as the building block of the future smart grid. They incorporate power electronics circuitry and high-frequency operation, which allows high controllability and enables bi-directional power flow, overcoming the limitations of conventional transformers. This paper presents a detailed analysis of the solid-state transformer, expounding the fundamentals, converter topologies, applications, and future challenges of the SST in a systematic manner. The paper discusses the necessity of improved replacement of the low-frequency transformers (LFTs) and presents the configuration of SST. It presents SST fundamentals in individual stages and explores its origin and evolution. The basic topologies, their specifications, and control strategies are also described. The applications of SST as a replacement of LFTs are discussed along with recent applications. The future challenges for real-time implementation of SSTs are explored, and research directions are proposed.
\end{abstract}

Keywords: solid-state transformer (SST); low-frequency transformer (LFT); power electronic converters; future smart distribution grid; SST topologies; renewable energy sources

\section{Introduction}

Transformers are the most vital component of the power system, as they play an essential role in the transmission and distribution of electrical power [1]. Being the fundamental components of the power distribution system, the conventional transformers were researched extensively and hence were developed to be cost-effective, exceptionally reliable, and highly efficient. Although they are fairly advantageous, they still have certain drawbacks, including power loss and temperature rise due to harmonics, poor voltage regulation under load, inadequate protection from abnormal currents, over-voltages, and overload. In addition to this, inadequate protection of the transformer from internal faults caused by breakdowns or arising from the core, the reflection of various unwanted input characteristics like voltage dip on the output side, and arduous efforts for the integration of renewable energy sources are of great concern. Along with having a large size and being bulky, the traditional transformers also lack adequate controllability and have an adverse impact on the environment due to excessive usage of transformer oil [2], which has contributed to the looming energy crisis we are facing around the globe.

To enable the power-grid for fulfilling the growing technological requirements such as integration with distributed renewable energy resources (DRER), distributed generation sources (DG), and distributed energy storage devices (DESD); charging techniques for electric vehicles (EVs), etc., the limitations of conventional transformers must be eliminated. 
This decentralization of power due to integration of various sources causes voltage deregulation [3] and power quality issues [4,5] and introduces harmonics [6] in the system, which cannot be controlled satisfactorily by LFTs. This highlights the requirement of intelligent equipment that incorporates technological advancements to overcome the deregulation of electrical power to expedite the energy demand.

With the technological advancements, high power converters are gaining ever-increasing importance in the power system through prominent applications such as integrating renewable energy sources into the power grid and playing a more proactive role in the transmission and distribution of power $[7,8]$. The application of solid-state electronics has enabled highpower electronic converters to control and convert electric power, facilitating it to emerge as one of the revolutionary technologies in the field of electrical engineering today.

The solid-state transformer (SST), also known as power electronic or high-frequency transformer, has gained popularity. It is considered the most suitable replacement for traditional transformers in future smart grids and is extensively researched for its application in power transmission and distribution systems [9-15]. Being energy-efficient, they are considered as one of the pioneering technologies of the future power system [16-18].

Figure 1a presents the configuration of traditional LFT operating at $f_{1}$. On the output side, the voltage level changes, but the frequency remains the same. However, in the SST configuration presented in Figure 1b, the transformer operating frequency $f_{T}$ is much higher than the LFT; and the output frequency is not necessarily the same as the input. The frequency $f_{2}{ }^{*}$ includes the possibility of dc voltage $V_{2}{ }^{*}$ i.e., $f_{2}{ }^{*}=0 \mathrm{~Hz}$.

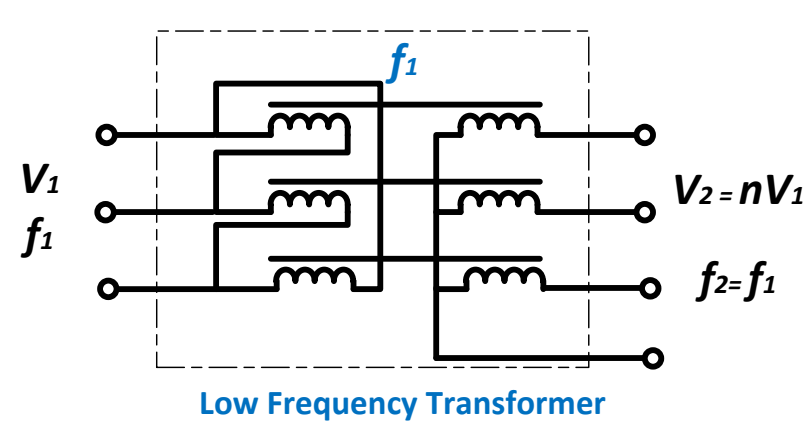

(a)

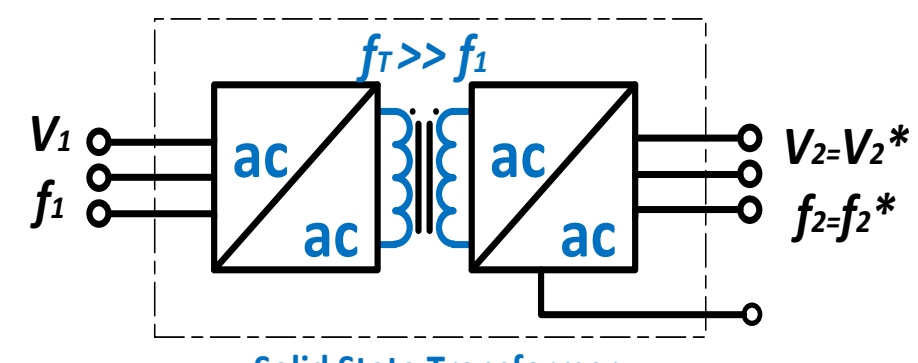

Solid State Transformer

(b)

Figure 1. (a) LFT configuration. (b) SST configuration.

From the SST configuration in Figure 1b, it is apparent that various potential functionalities that were non-existent in the traditional transformer are present in SSTs. The utilization of the power-electronics interface allows the operation at high frequency, and the intermediate DC-DC conversion stage also offers numerous benefits. SSTs provide various advantages such as voltage sag compensation, control over power flow, reactive power compensation, fault isolation, ability to provide dc output, etc. Various projects $[9,12,16,19,20]$ are directed at promoting advancements in SST technology, as they are considered the most fundamental unit of the future smart grid. SSTs promote bi-directional power flow in the distribution grid, allowing the interfacing of either dc or ac to enable the integration of renewable energy sources like photo-voltaic, and facilitate power flow from various micro-grids [11,21-24]. As SST technology evolves, they are compelled to be involved in energy markets to fulfill the ever-increasing energy demand in the future as they facilitate controlled, regulated, and efficient power supply from main-grids and micro-grids. With micro-grids emerging as great contributors to the power demand and supply cycle alongside the main grid, the de-regulation and decentralization of power will be evident in the future [25]. To regulate such power flow, intelligent devices like SST will be essential.

They are also well suited for various renewed applications such as high-frequency transmission in distribution grids; implementation of micro-grid in marine [26], naval [27], 
subsea [28], oil-drilling applications [29]; utilization of the concepts of distributed propulsion in aircraft; and in traction where it eliminates the constraints of weight and size significantly. Although SSTs have significant advantages, there are still certain limitations to overcoming their real-time implementation. The LFTs are more efficient than the SSTs; they have better robustness, are more economical, and are highly compatible with the current power grid and distribution system, along with their protection and isolation schemes. At present, LFTs seem preferable, but the looming concern of the environment compels us further to explore SST technology as a suitable eco-friendly alternative.

This paper presents a review of the solid-state transformer and its technologies. The article is organized in the following manner: Section 2 illustrates the SST fundamentals and their distinct stages. Section 3 describes the basic SST topologies along with the functionalities, specifications, and control strategies. Early high-frequency converters are discussed as well. Section 4 explores the various application of SST in the power system. The future challenges to the SST technology are reviewed, and research directions are provided in Section 5.

\section{SST Fundamentals}

SST utilizes power electronic converters, and depending on their configurations, SSTs are classified into various topologies. To elaborate on the key concepts of SSTs, the most popular three-stage topology shown in Figure 2 is deemed best suited since this particular topology simplifies the control design and can provide all functionalities.

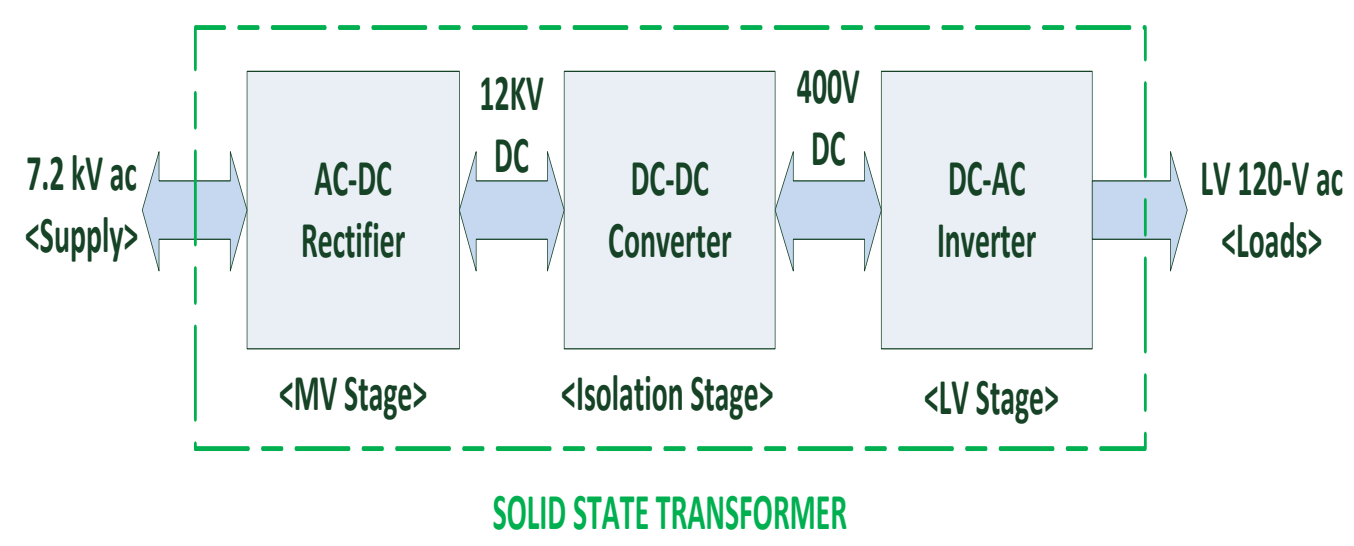

Figure 2. Stages in SST.

A basic SST comprises three distinct stages:

1. Medium Voltage (MV) Stage: Medium level voltage includes voltages higher than $1 \mathrm{kV}$ but lower than $100 \mathrm{kV}$. The three-phase AC voltage of frequency $50 / 60 \mathrm{~Hz}$ is supplied to SST, converted into DC voltage through power converters. This MV stage can be called the rectifier stage. It converts AC into DC. In contrast with other electronic converters with low-voltage inputs, the power converters in SST must interface with much higher voltage levels of ac and dc. SSTs typically operate at higher power levels associated with their typical applications in traction, power grids, etc., so these power converters must have the ability to tolerate connection to MV. In grid applications, where weight and size do not necessarily play a significant role, SSTs can offer harmonic filtering through this rectifier stage by employing a PWM (pulse width modulation) rectifier, which is much needed in the existing grid system and the future smart grid.

2. Isolation Stage: This stage isolates the high-power stage from the low power stage using the Medium Frequency (MF) transformer, the isolation stage. In this stage, the DC$\mathrm{AC}-\mathrm{DC}$ conversion occurs. The $\mathrm{DC}$ is converted to $\mathrm{AC}$ of a much higher frequency in a few $100 \mathrm{~Hz}$ to a few $\mathrm{kHz}$. In the next $\mathrm{AC}-\mathrm{AC}$ conversion step, a high-frequency transformer is employed to step down the voltage magnitude. The operation of the transformer at a 
higher frequency allows full utilization of the core magnetic properties. In the next step, AC-DC conversion occurs where this high-frequency AC is converted into DC [30].

The operation of the isolation transformer at a high frequency reduces the size and weight of the SST. For the same power transferred P, keeping winding current density J and the maximum core flux density Bm constant, the transformer size/volume $\mathrm{V}$ in terms of operating frequency $f$ is given by Equation (1) as

$$
\begin{gathered}
A w \cdot A c=\frac{\sqrt{ } 2}{\pi} \cdot \frac{P}{k_{w} B_{m} J f} \\
\Rightarrow V \propto(A w \cdot A c)^{\frac{3}{4}} \propto \frac{1}{f^{\frac{3}{4}}}
\end{gathered}
$$

where $k_{w}$ is the winding window filling factor, $A c$ is the cross-sectional area of the core, and $A w$ is the window area of the winding. From the above equation, it is apparent that by increasing the operating frequency of the transformer, its physical dimensions can be reduced. The operation of SSTs at higher frequencies makes them suitable for specific applications like traction, where weight and volume constraints hinder higher efficiency. This reduction in size or/and volume of the SSTs, enabling the improvement in the performance of traction equipment, has attracted much attention of manufacturers [11,31-37]. Apart from applications where SSTs can help achieve various benefits due to their reduced weight and size, their additional characteristics, such as allowing bi-directional power flow, reactive power compensation, DC links, etc., can be advantageous in other applications. Therefore, SST technology is considered a crucial component of the future power system.

As SST utilizes multistage power converters for various applications, these converters must have a high switching frequency. Along with increased switching frequency, switching losses will also increase inevitably. This is also considered a significant hindrance to improving efficiency and should be considered during design and manufacturing.

3. Low Voltage (LV) Stage: LV range contains voltages ranging from 50 to 1000 volts. In this LV stage, DC-AC conversion occurs; hence, it is also called an inverter stage. The frequency of converted AC is usually $50 / 60 \mathrm{~Hz}$. Unlike LF transformer, SST also offers controllability through this LV stage. It allows controlling input and output voltages, currents, and power flow through power converters and MF transformers employed in typical SST. In addition to this, it permits controlling the output frequency as any desired output frequency can be achieved in DC-AC conversion. Reduction in weight and size of the high-frequency transformer is incredibly advantageous for SST. Still, consideration of other components like power converters, heat sinks, control circuitry, etc., is also essential for overall reduction. The efficiency and controllability of the SST depend on the circuitry and the configuration of the converters and their stages. In contrast with LFT, SST technology has numerous topologies. Each topology possesses specific sets of advantages and limitations along with the fundamental characteristics of SST, as discussed in the next section.

\section{SST Topologies}

With the critical characteristics of SSTs employed, McMurray proposed the realization in 1968 as "Converter circuits having high-frequency link" [38]. The non-resonant AC-AC power converter with a high-frequency link as proposed in 1968 by McMurray is presented in Figure 3. 


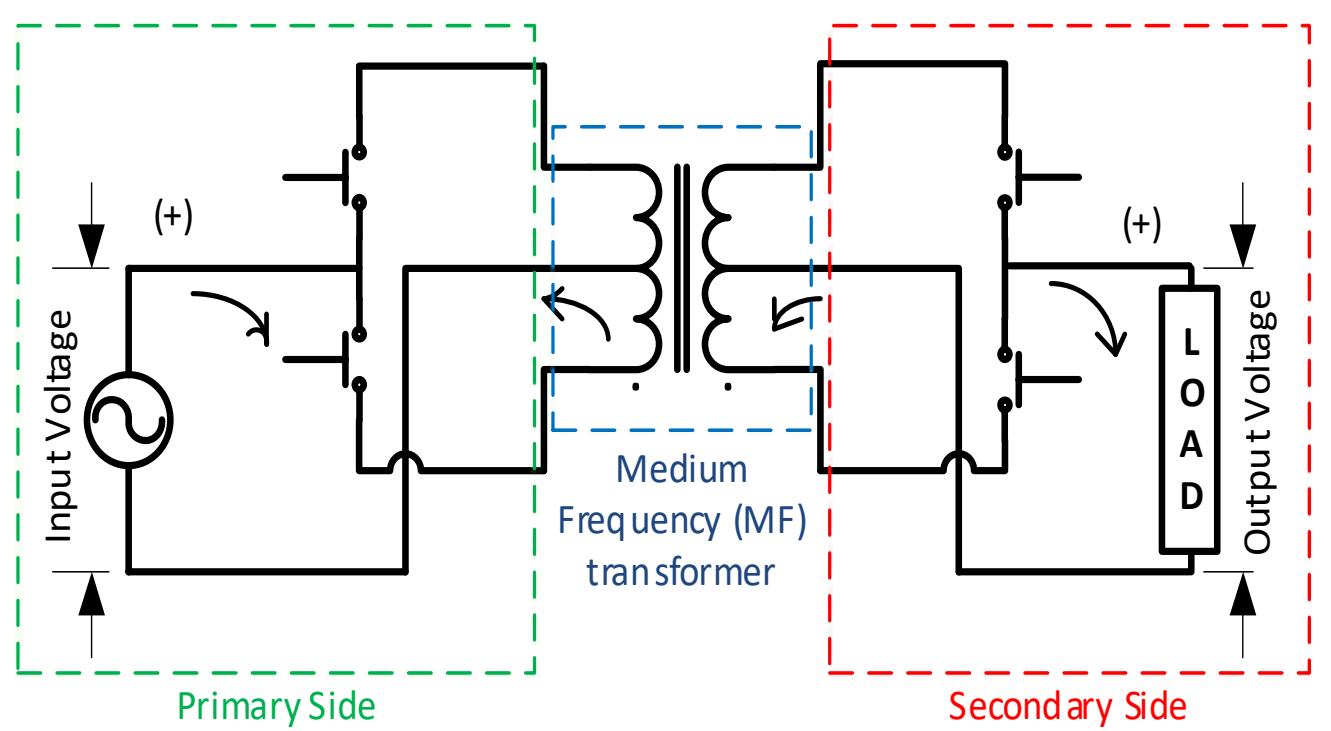

Figure 3. A non-resonant AC-AC power converter with a high-frequency link as proposed in 1968 by McMurray.

It is a primary, non-resonant circuit that utilizes four-quadrant turnoff switches to chop ac input voltage. The switches have a combination implemented as an antiparallel connection of transistors with series diodes to generate an AC voltage of high frequency supplied to the MF transformer. The output voltage can be controlled by phase-shifting the switching instants of secondary to primary side switches.

For the facilitation of the commutation of thyristors, the transformer current should be shaped more sinusoidal. In 1968 itself, McMurray proposed adding a series resonant capacitor to "Converter circuits having a high-frequency link." This is known as "Half cycle discontinuous conduction mode series resonant converter" or HC-DCM SRC [39,40]. It features a fixed voltage transfer ratio of MF transformer by adjusting the power flow automatically in response to any change in voltage. This circuit also allows for soft switching, which reduces switching losses and improves converter efficiency, which is an excellent achievement in developing SST technology and is implemented in various topologies.

These converter circuits cannot be directly connected to MV because blocking voltages of power semiconductors was pretty less. Therefore, we utilize a multi-level converter that employs a cascaded H bridge and has Input Series Output Parallel (ISOP) structure where cells are connected in series at their input side terminals and in parallel at their output side terminals to ensure self-balancing. The circuit is known as a "Fast response stepped wave switching power converter" [41].

Although this concept of SST proposed by McMurray in1968 was revolutionary, its implementation in various applications was quite a challenge. It was followed by researchers of the US Navy presenting another AC-AC converter in 1980, which utilizes a buck converter to enhance the output voltage [39,42]. Although it was the first working prototype, it still had various limitations. It was followed by a series of proposals, each with its advantages and limitations.

In the past decades, extensive research and great efforts have been made to improvise the SST technology through various topologies. SST employs the multi-level converters for better performance and utilizes a multistage topology to support its high voltage requirements [43]. Multiple strategies to control the SST converters have also been proposed, but they vary for different topologies. However, most of the topologies can be derived from a few basic topologies. These basic topologies, along with control strategies, are discussed below.

1. Single-Stage: In single-stage topology, High Voltage AC (HVAC) is stepped down by using a high-frequency transformer to Low Voltage AC (LVAC), as shown 
in Figure 4 [44-46]. In this topology, four-quadrant switches regulate voltage by phaseshifting between the primary and secondary side switches. Harmonics can also be controlled by phase-shifting these switches so that output voltage waves acquire a more sinusoidal nature [47].

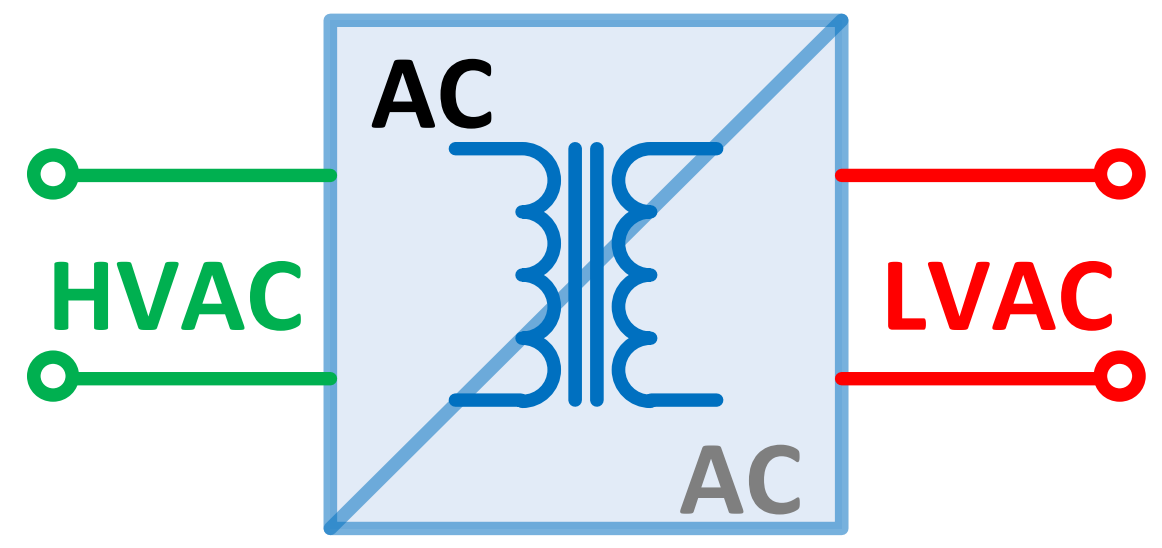

Figure 4. Single-stage topology.

The single-stage SST has a low voltage conversion ratio due to the low switching frequency of the power converter. Although soft switching is an effective method of reducing switching losses caused by high switching frequency, it can be implemented within a specific rated load limit.

A $2 \mathrm{~kW}, 110 \mathrm{~V} / 20 \mathrm{~V}$ single-stage, AC/AC, two-level converter allowing bidirectional power flow with maximum power-point tracking was proposed in [48] that utilized the PWM for control. Another $10 \mathrm{kVA}, 208 \mathrm{~V}$ single-stage AC/AC, two-level converter allowing bi-directional flow that utilizes ZVS (zero voltage switching) as the control method was proposed in [49]. A $2 \mathrm{~kW}, 400 \mathrm{~V} / 208 \mathrm{~V}$ Single-stage, AC/AC, matrix-based converter using predictive control was proposed in [50]. Recently, a new single-stage high-frequency link-based single-phase SST topology was proposed in [51]. Switching tube multiplexing is carried out to reduce the number of switching devices. The SST inductor current is minimized by switching different control modes to minimize the conduction losses of IGBTs. The control extended phase shift control (EPS) based to make implementation easy.

2. Two-Stage: Two-stage topology converts HVAC into LVAC similar to one-stage topology, utilizing an additional DC link. This topology has two variations of its configuration.

In a two-stage topology with an LVDC link, AC is stepped down by a high-frequency transformer and converted to DC using power converters. This stage LVDC link is implemented; then this DC is converted to AC as shown in Figure 5a [52-55]. This LVDC link facilitates the integration of DC loads and renewable energy sources into the grid.

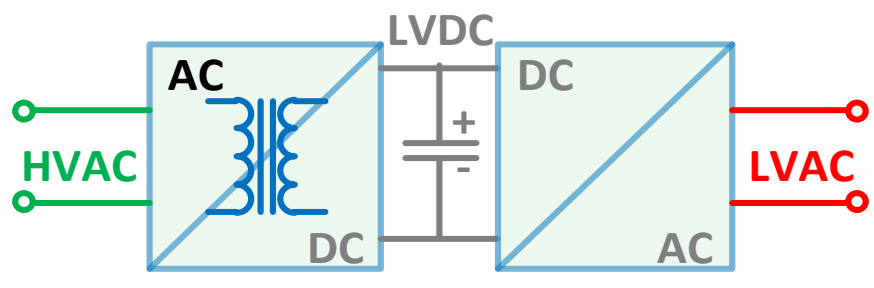

(a)

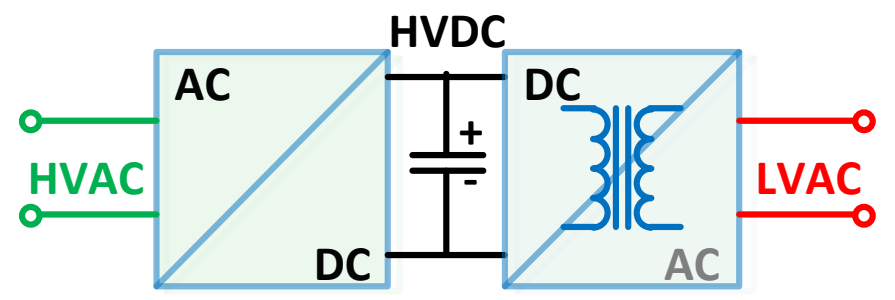

(b)

Figure 5. (a) Two-stage topology with LVDC link (b) Two-stage topology with HVDC link.

In a two-stage topology with an HVDC link, AC is converted to DC utilizing power converters, and then, an HVDC link is implemented. This second stage converts DC and 
steps it down using the high-frequency transformer to LVAC, as shown in Figure 5b [55]. The HVDC link can be implemented in HVDC transmission. This two-stage topology offers higher efficiency and better reliability by realizing soft switching.

A 5 kVA, $220 \mathrm{~V} / 380 \mathrm{~V}$ two-stage, direct AC/AC high-frequency link, dual bridge matrix converter topology utilizing PWM control was proposed in [49]. In [56], a $5 \mathrm{~kW}$, 3300VAC/380VDC two-stage, cascaded H-bridge topology that allows bi-directional power flow was proposed. The proposed converter utilizes phase shift as the control strategy. Recently, a two-stage topology that provides an LVDC port or medium-voltage DC (MVDC) port was proposed in [57], and the dual loop-based closed-loop control was used for output voltage.

3. Three-Stage: Three-stage topology shown in Figure 6 utilizes HVDC as well as LVDC link, HVAC is supplied to the AC-DC rectifier stage, which offers various advantages including voltage regulation across HVDC link, bi-directional power flow, VAr compensation, [58] and harmonic filtering by achieving more sinusoidal wave shape [59-61]. In the second stage, DC is converted to high-frequency AC to be stepped down through a highfrequency transformer and be converted back to DC by utilizing the Double Active Bridge (DAB). The DAB allows the inter-facing of the HVDC link to the LVDC link. Through the high-frequency transformer also provides galvanic isolation [58]. The DC voltage of the second stage is then transferred through the LVDC link to the third stage, where this DC is converted back to AC at a frequency of 50/60 Hz.

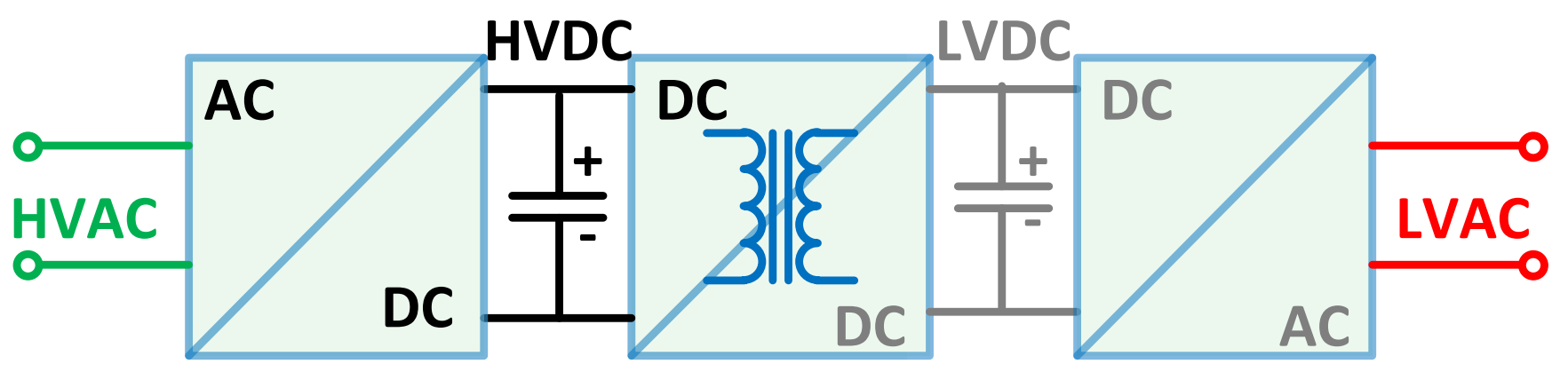

Figure 6. Three-stage topology.

A three-stage topology with suitable control strategies was deemed appropriate for implementation among all three topologies and their alternates. It has higher efficiency [62] and better power controllability. However, it utilizes many passive devices, which is a considerable disadvantage [63].

A 2 kW, 600VDC /200VDC, three-phase modular multi-level DC/DC converter allowing bi-directional power flow was proposed in [64]. The control methods for the converter include PWM, ZVS, and the dual-phase-shift method. Recently, in [65], an SST topology adopting three-stage cascade control of input isolation output capable of providing highvoltage and low-voltage DC bus, which can realize DC input and output and has strong compatibility, was studied. The front-end rectification stage adopted the double closedloop control strategy of the current inner loop voltage outer loop with the fast current response, and the DC-DC stage adopted the voltage-followed phase-shift full-bridge ZVS control method.

Table 1 presents four main modern SST topologies, namely neutral point clamped (NPC) topology, flying capacitor converter, cascaded H-bridge (CHB) multi-level inverter configuration, and modular multi-level (MMC) converter [66].

Other notable topologies for SST include the transistor clamped converter, dynamiccurrent (or Dyna-C), matrix type, isolated back-end, isolated front-end, etc. With the advancements in the field of $\mathrm{SiC}$ power semiconductor technology, the devices such as $\mathrm{SiC}$ IGBTs and SiC MOSFETs, which have significantly higher blocking voltage, may enable the usage of single-cell topology [37]. 
Table 1. Comparison of various multi-level topologies.

\begin{tabular}{cccccc}
\hline & Expandability & Capacitor Size & Inductor No. & Capacitor No. & Semiconductors No. \\
\hline Neutral point-clamped & No & Low & Low & Low & High \\
Flying capacitor & No & Low & Low & Low & Low \\
H-bridge cascaded & Yes & Medium & Low & High & Low \\
MMC & Yes & High & High & Low & Low \\
\hline
\end{tabular}

Multistage topologies utilize DC links, either HVDC link, LVDC link, or both. These links provide a direct connection to various devices or sources that would otherwise need some sort of bridge. LVDC link allows direct point for integrating various renewable energy sources, energy storage devices, and DC loads, thus removing the requirement to convert to AC before integration. On the other hand, the HVDC links in SSTs topologies are used in HVDC transmission as HVDC can be transmitted directly through these HVDC links. HVDC transmission is making a massive comeback with the development in SST technology and its improvised topologies, which offer direct transmission through HVDC links and provide HVDC voltages in its DC conversion stages through power converters. Various applications involve a mixture of AC and DC devices, such as micro-grid, photovoltaic, home appliances, etc., yet another domain of application of SST topology. As multiport SST features various input and output voltage levels, both AC and DC can regulate and compensate active power and reactive power, which can be utilized in DC charging stations or charging stations of future electric vehicles, which is a phenomenon of the 21st century. This reactive power compensation is a massive concern of the current and future grid; however, this proposed application has huge disadvantages and requires much greater effort and research. Recently, the emergence of power devices such as power IGBTs, SIT, SITH, etc., alongside the innovation of SiC technology, has enabled the implementation of SST technology in recent years.

\section{Application}

The distribution grid is ever-changing and is becoming more advanced with time. Integrating renewable energy sources and storage devices is a key characterizing feature of the future smart grid. SST emerges as an excellent alternative for minimizing and even eliminating the requirement of conventional transformers that utilizes oil for cooling and insulation purpose. With the increasing application of SST, the mineral oil consumption reduces, and consequently, its adverse impacts on the environment will be minimized. With the looming energy crisis, the application of the SST should be studied and researched extensively. Potential applications are thus shown in Figure 7. Applications of SST as a superior alternative to the LFT and recent applications are explored below.

The potential applications of the SSTs are shown in Figure 7 and are discussed below:

a. Traction With the emergence of power electronics, power electronic traction transformers (PETT) have gained much popularity. Various designs and configurations of PETT utilizing SST technology are proposed in numerous traction applications [34,67-72], as they offer the advantages of improving power density and efficiency simultaneously along with weight and space reduction [37]. Figure 8 demonstrates an SST-based traction system, in which a low-frequency transformer is effectively replaced by the SST. In 2011, ABB proposed a 1.2 MVA PETT prototype with a 9-module CHB plus LLC resonant converter for a $15 \mathrm{kV} / 16.7 \mathrm{~Hz}$ railway grid having an efficiency of around $96 \%$. Another PETT configuration based on low-voltage IGBTs instead of its popular alternative, i.e., high-voltage IGBTs, was proposed for better efficiency and lower cost than the conventional PETT configuration with the modular series-parallel structure in [73]. Recently modular multi-level converter technology has emerged as a promising technology. A single-stage SST topology based on modular multi-level converters utilizing the concept of interleaving converters and integrated power stages has been studied and experimentally 
validated in [74]. It is deemed suitable for traction application with an efficiency of $87 \%$, power factor as high as 0.99 , and low harmonic distortion of $3.7 \%$ to the input current. Research is still going to explore traction transformers further and ensure their satisfactory implementation.

b. Smart grid integration Another application of SST is the integration of micro-grids into the smart grid. The DC link in the SST topologies is greatly utilized in these applications. The integration of renewable energy resources (DRER) and distributed energy storage devices (DESD) is the most desirable application of SST, as the microgrid structure is a suitable alternative to fulfill the energy demand [9]. An SST base micro-grid structure is presented in Figure 9. A quad-active-bridge (QAB) converter is proposed in the paper [75] as the fundamental component of an MMC-based SST for integrating DER and distributed energy storage systems (DESS) in the distribution grid. The DC link in SST eliminates certain frequency and phase requirements, which were fundamental in AC while integrating. Enabling bi-directional power flow is yet another advantage of SST $[16,76,77]$. The behavior of one such SST is investigated in [78]. The system of $100 \mathrm{kVA}$ Transformer less Intelligent Power Substation (TIPS) in the paper is investigated when it is integrated with the DESD modeled through a battery. Electric vehicles (EV), as the future of automobiles, require charging stations for their implementation. These charging stations will enable the integration of electric vehicles into the grid when they are plugged into charging. The paper in [79] presents a review of the charging techniques of EV and proposes an on-road charging system with energized lanes for EV. This will allow them to draw power from the grid, raising concerns regarding its impact on the power grid. However, such charging stations are being implemented utilizing SSTs and have shown much progress and high efficiency compared to other alternatives [80]. Harmonic filtering is another feature that will aid the integration of various sources and devices. The capability of harmonic filtering depends on the switching frequency of the SST [17]. The SST can also be used as the unified power quality conditioner (UPQC) to eliminate both the shunt and series transformers.

c. Reactive Power Compensation Unlike conventional devices that only utilize passive components, power electronic devices employ active components. These active counterparts draw active and reactive power from the grid, which causes an imbalance between them. Although the tap-changing option of the LFT allows the transformer to control the voltage to meet the active power demands, it has limitations of margin voltage and the inability to change the frequency of the tap changers [81]. The traditional transformer is unable to compensate for the reactive power loss. Therefore, the power engineers employ the capacitor banks, Static VAr Compensators (SVCs), Static Synchronous Compensators (STATCOMs), etc., to compensate for this deficit [82]. The balance between active and reactive power is essential to regulate power flow and improve the power factor. SSTs can enhance reactive power compensation along with further reducing its power loss and cost [83]. In [84], SST based on a doubly fed induction generator (DFIG) topology has been proposed for reactive power compensation, eliminating reactive power compensator devices. In [85], system utilizing SST in the wind energy system is presented. It offers a family of wind energy systems utilizing SST, which enables control of active power and compensation of reactive power along with improved voltage regulation. It presents a simulation study for a wind farm (WF) driven by squirrel-cage induction generators is, and the wind energy system interfaced by SST is shown in Figure 10.

d. Fault Isolation and Limitation Traditionally in medium-voltage AC power systems, mechanical circuit breakers clear and isolate faults enabling the continuous power supply. Although they are fast-acting and effective, the power interruption for critical loads is inevitable. SST, being an intelligent equipment, can isolate the loads from fluctuations and fault disturbances by supplying the power from micro-grid structures to maintain uninterrupted power supply to crucial loads [17]. For improvising 
the fault-tolerant capability of SST, an approach is proposed and validated in [86] that utilizes the time before restoration to analyze current and voltage deviations. A solid-state fault isolation device (FID) is capable of being a recloser as well as a sectionalizer. Its usage for short circuit current has already been verified [87]. Another solid-state fault isolation device (SSFID) is proposed, validated, and tested in [87]; elaborates the criteria for the selection of a solid-state fault isolation device (FID) to be used in power-electronic based distribution systems (PEDS) and draws a contrast between the fault isolation power electronics-based system (PEDS) and the traditional distribution system. It proposes and validates an FID topology, and the snubber circuit design of a $6.5 \mathrm{kV}$ FID is presented.

e. Voltage Regulation The voltage regulation is the essential characteristic of any basic SST. Most of the SST topology offers an AC to DC conversion stage alongside the DC capacitor. This rectifier stage allows any AC input voltage to be converted to DC, which can be controlled at this stage through power-width modulation. The PWM rectifier can boost the DC voltage keeping the power factor unity. Then, this DC voltage is converted back to AC at any desired voltage level and frequency to be supplied as output. The utilization of the PWM rectifier makes the output voltage unaffected by any voltage dip and sag in supply and allows regulated voltage supply and controllability. Additionally, the output voltage wave will be free of harmonics and purely sinusoidal with a unity power factor providing almost ideal voltage regulation [88]. A $20 \mathrm{kVA}$ SST with an input voltage of $7.2 \mathrm{kV}, 60 \mathrm{~Hz}$, and output voltage of $120 / 240 \mathrm{~V}, 60 \mathrm{~Hz}$ is modeled and tested under load change test in [89] to study voltage regulation. On the other hand, [90] proposes a generalized model of SST in which by controlling the individual voltage ports of the SST voltage as well as power can be regulated more effectively and flexibly.

f. HVDC Transmission HVDC transmission offers various advantages over AC transmission, as it is independent of any voltage, frequency, and phase requirements associated with transmission and synchronization of AC. Heating loss due to harmonics will be eliminated along with other advantages as well. In the past, the generation of high voltage DC was still a concern, and then its utilization also faced many hurdles as most of the appliances operated on AC. SST suitably provides a solution to it through the DC link utilized in its topologies [91]. It also uses power electronic devices to convert AC and DC interchangeably. The HVDC link can be greatly useful in HVDC transmission. The LVDC link can improve the accessibility of DC in power systems as it facilitates the integration of devices with the grid [82]. HVDC transmission is a promising application of SST and research continues to explore its implementation in various applications. In [92], a concept for controlling and expanding the HVDC transmission was proposed, enforced by the simulation. Recently, ref [93] investigated the SST applied for the HVDC transmission from the offshore windfarm. A $200 \mathrm{~V}, 5 \mathrm{kVA}, 3 \mathrm{kHz}$ middle-frequency transformer for solid-state transformer with amorphous and nanocrystalline core materials are tested and analyzed. A Fault-tolerant Cell Design for MMC-based Multiport Power Converters was proposed in [94] to overcome the fault-tolerant capability of MMCs. The proposed cell structure, capable of blocking the DC short circuit current, is deemed feasible for the application of HVDC transmission. Various other applications of SST include energy router in future smart grids, the interface of hybrid DC and AC micro-grid systems, induction heating applications, single-stage bidirectional SST for lighting, implementation in wind energy power plant, regulating bi-directional power from micro-grid structures, interphase AC conversion, i.e., three-phase to single-phase or vice versa along with other conversions, smart regulation at the domestic level, etc. 


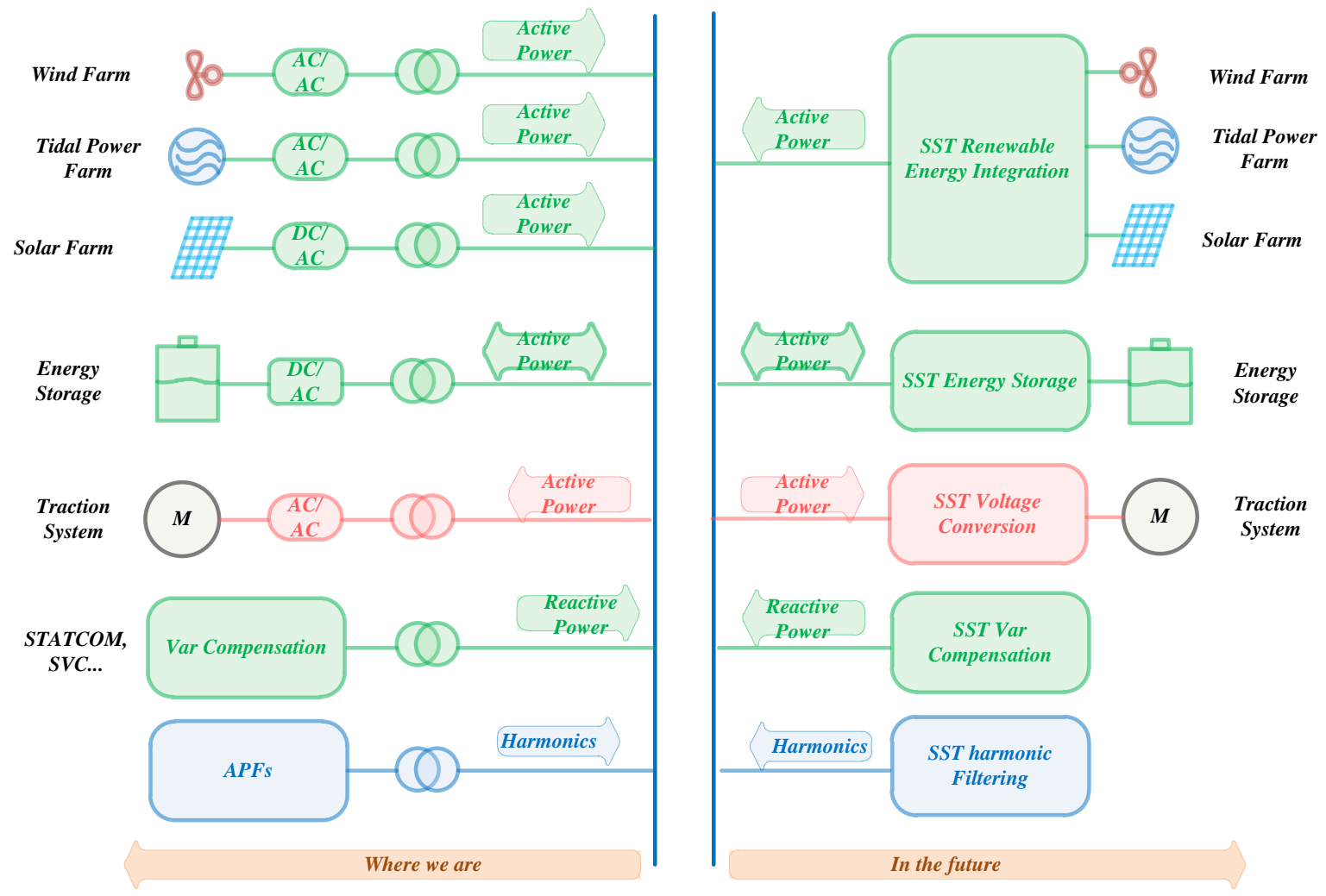

Figure 7. Potential applications of the SST.

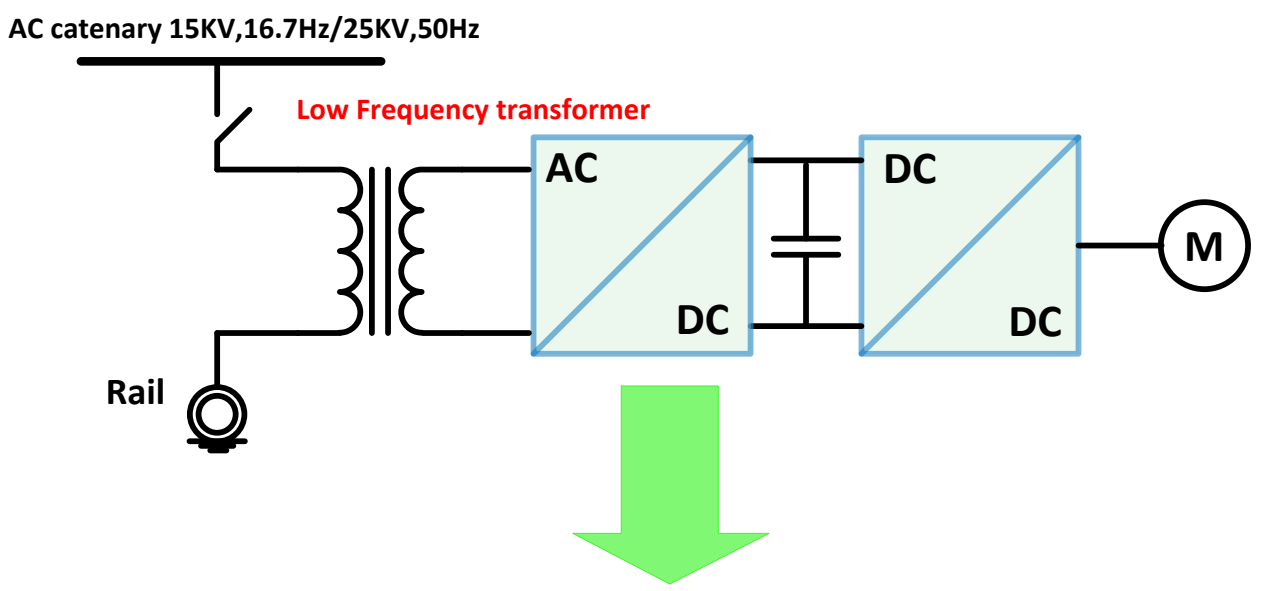

AC catenary $15 \mathrm{KV}, 16.7 \mathrm{~Hz} / 25 \mathrm{KV}, 50 \mathrm{~Hz}$

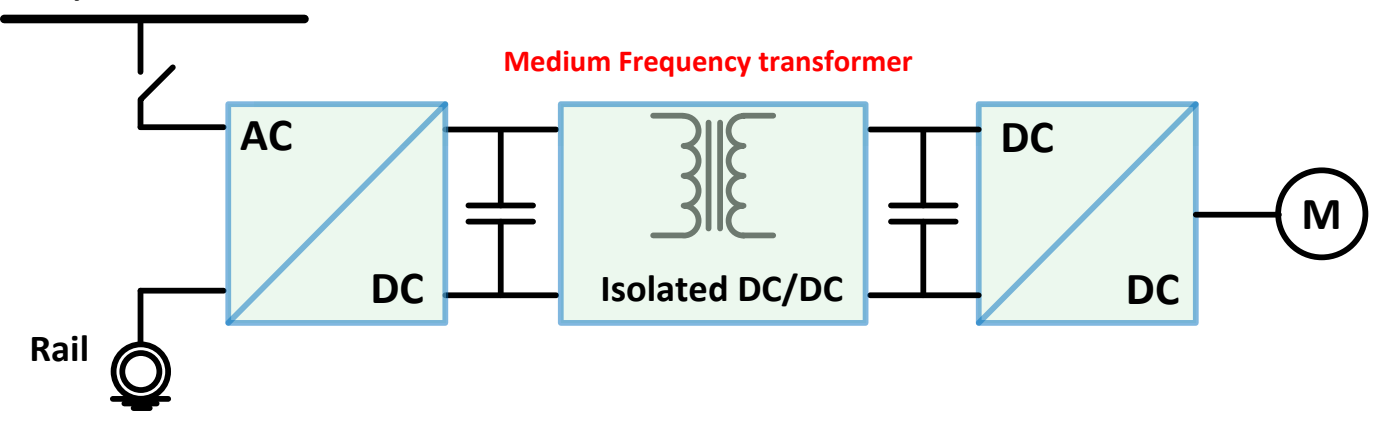

Figure 8. SST-based tractions system. 


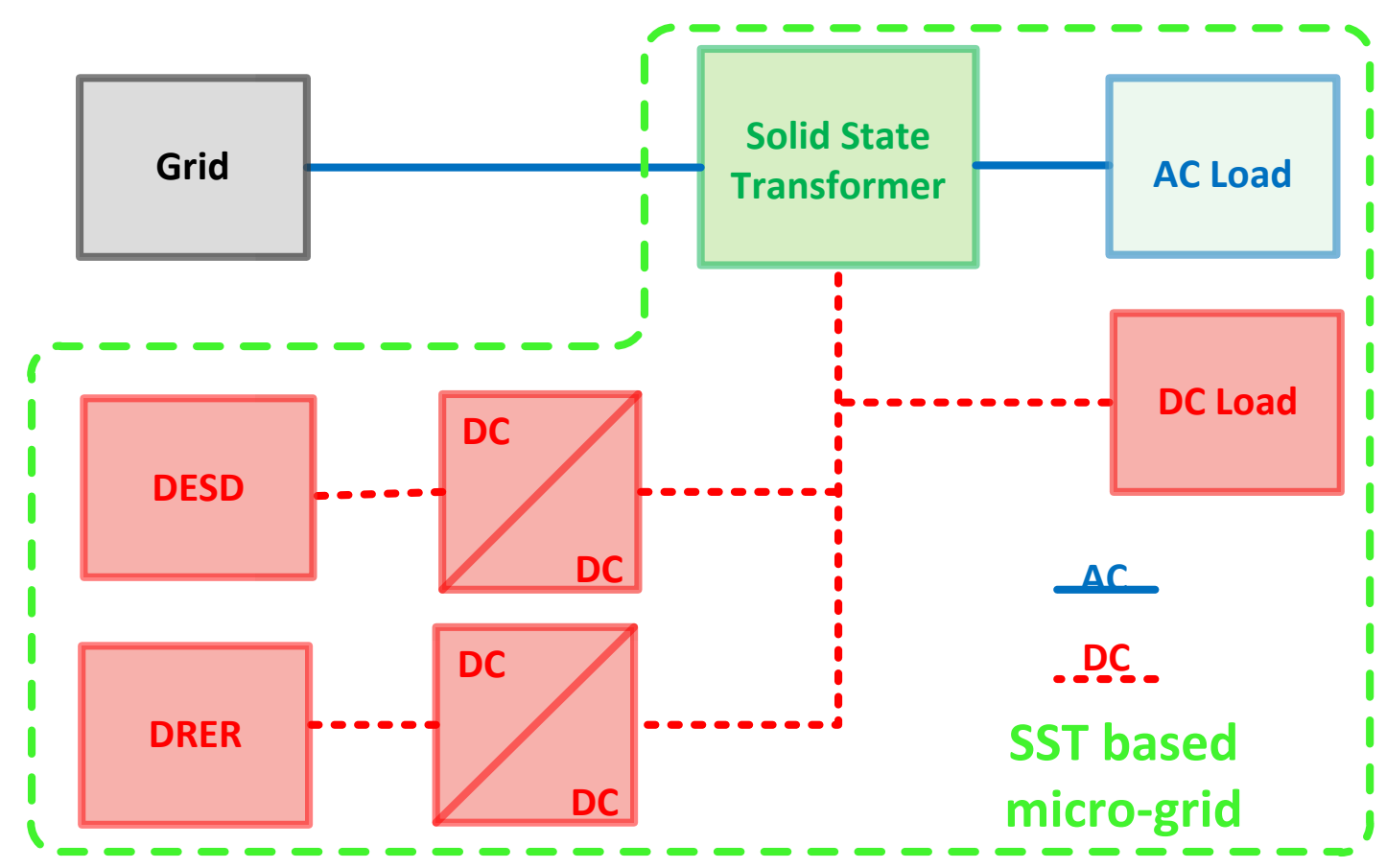

Figure 9. SST-based microgrid architecture.

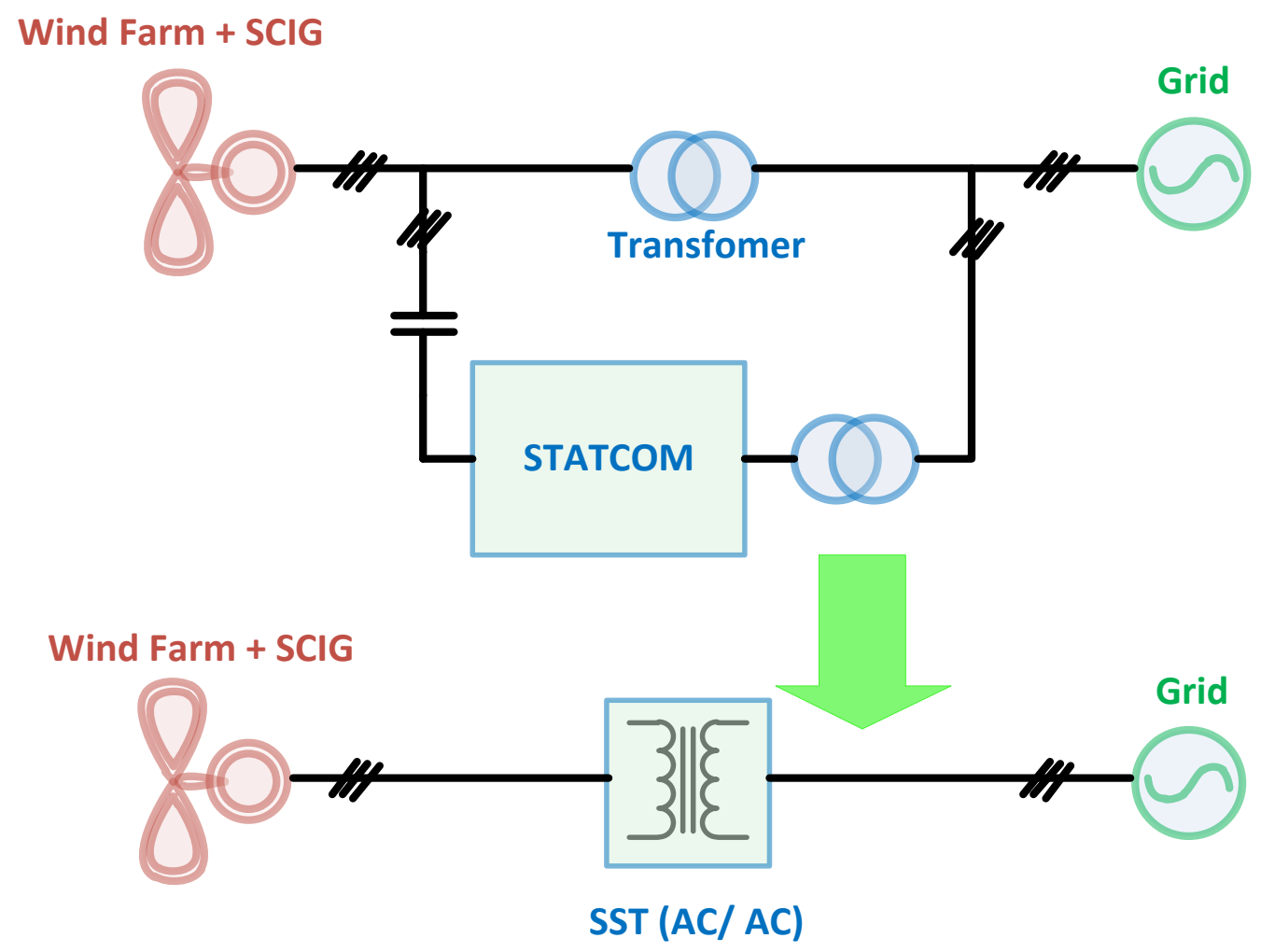

Figure 10. Wind energy system interfaced by SST.

\section{Future Challenges}

The development of SST in the recent decade has garnered much attention from commercialists as a replacement LFTs. The commercialization of SST will be the governing factor of its development and implementation. The limitations of SST in applications of 
power transmission and distribution systems emerge as future challenges to the development and commercialization of SST technology. The implementation of SSTs and as the vital building block of the smart distribution grid will lead the way to sustainable development. Only by overcoming these hurdles of limitations will SST be able to realize its full potential to emerge as pioneering technology of the future. The following are the significant future challenges that are compromised by SSTs

a. Cost The cost of SST is relatively much higher than that of LFT [95]. The major part of SSTs cost is its passive components like a high-frequency transformer and heat sinks. The control circuitry is expensive as well. With the evolution of SST for specific applications, particular specially designed circuitry will be inevitably used, further contributing to its higher price. The authors of [85] provide the cost breakdown for the proposed prototype of estimated USD 10726, which is as follows: $15 \mathrm{kV} \mathrm{IGBT}$ and driver (32\%), high-frequency transformer (16\%), DC capacitors $(16 \%)$, heat sink and fan $(9 \%)$, controller board (8\%), IPM and driver (7\%), filter inductor $(5 \%)$, sensors ( $4 \%)$, auxi-power supply (1\%), and others $(2 \%)$. Notably, the major contribution is of high voltage power devices, high-frequency transformers, and DC capacitors. It is estimated that the cost of production of $20 \mathrm{kVA}, 7.2 \mathrm{kV}-120 \mathrm{~V} \mathrm{SST}$ is about USD 1000-2000, and the market price will be much higher. However, the market price for a single-phase $25 \mathrm{kVA}, 7.2 \mathrm{kV}-120 / 240 \mathrm{~V}$ pole mount transformer is around USD 1500. So, the cost of SST is much higher than the conventional transformers. However, speculations regarding reducing the cost of SSTs associated with mass production for wide applications are being made. The main contributor to this cost reduction will be electronic circuitry [96]. It is possible to witness a decline in the cost of SST with the development of SST technology, as innovative techniques contribute to the cost reduction. A cost-effective solution is to eliminate the current sensor in the DC/DC stage of cascaded multi-level converter utilizing the current sharing strategy. Instead, it uses the active power component of the duty cycle in the rectifier stage as the feedback signal for the power balance controller in the DC/DC stage [97]. The recent emergence of SiC technology is speculated to lower the cost of SST by reducing the number of power electronic devices. Various topologies incorporating $\mathrm{SiC}$ technology could be researched for effective cost reduction of SST.

b. Efficiency The required overall standard efficiency for the distribution transformer of any power rating must be above 97\%. Most traditional transformers' usual efficiency is greater than $98 \%$, but SSTs are not efficient enough. According to the standard for comparative evaluation of efficiencies of liquid immersed and dry-type distribution transformers, the Department of Energy (DOE) of the USA [98]. From the standard, the overall efficiency of liquid immersed transformers was $99.5 \%$, which is relatively high. It was achieved due to effective heat transfer from the core of the transformer by using transformer oil. This high-efficiency traditional transformer is a considerable challenge and a big hurdle in the implementation of SST. SSTs utilize high power converters, which are not very efficient due to high switching frequency and the switching losses associated with it, thereby affecting the efficiency of SSTs in turn [37]. Another concern is that the efficiency of SST reduces significantly if not operated in the range around the rated load [99]. Although having efficiency satisfying the standard efficiency requirement is sufficient for SSTs, it offers additional advantages. However, it is still incomparable to the almost perfect efficiency of the liquid immersed transformer. Research is proposing the efficiency of SST in the range of $96 \%$ to $98 \%$, but the actual realization is not yet achieved [95]. The switching losses can be reduced by the use of $\mathrm{SiC}, \mathrm{GaN}$, and wide bandgap devices instead of Si to improve the efficiency of the SST. The proper magnetic core selection is essential in improving efficiency by reducing the power losses at high frequency. Proper selection of excitation voltage waveform is significant in reducing the core losses. However, MMC can potentially generate controllable multi-level 
excitation ac voltage to improve efficiency [100]. Research is needed for the most suitable magnetic core material for SST.

c. Reliability Extensive efforts were made so that LFTs have high reliability, are used extensively in harsh conditions, and require less maintenance. However, SSTs are fairly reliable but not as much as LFTs because they use more active components instead of passive components. Additionally, they need extensive and regular care [85]. Reliability depends on device rating and redundancy. For a non-redundant system, higher rating semiconductor devices mean high reliability. However, one more redundancy applied to a system will increase system reliability significantly up to a certain number for a redundant system. The application of numerous semiconductors in their various configurations increases the possibility of failure and makes it less reliable [101,102]. A reliability model was proposed in [103], in which having a higher rating and lower redundancy number make topologies sufficiently reliable. However, it is applicable only for specific topologies of SST.

d. Protection Under normal conditions, SST protects the load from faults, voltage sag, and fluctuations arising from the power grid. However, SST also requires protection of its own internal devices and circuitry from high current during abnormal conditions such as DC bus short circuit on the MV side [104-106]. SSTs are expected to withstand abnormal conditions, which include external faults, grid faults, converter level faults, DC-Bus faults, etc. Various protection schemes to tackle these situations are Short-Circuit Current Limiting Scheme, Circuit Breakers, Fuses, etc. [107]. The MV side DC bus short-circuit condition is the most dangerous, as it causes a high in-rush current in the switching devices. In [108], a DC short-circuits current limiting scheme utilizing the bi-directional switch approach was proposed to protect the system under abnormal operations. A high impedance grounded path-based method is proposed for SST in [104] for the SSTs whose MV side AFECs are made of three singlephase multi-level converters connected in star $(\mathrm{Y})$ connection. However, it cannot be used if there is no common or neutral point on their MV side AC terminals. In [108], a bi-directional-switch-based approach is proposed to protect the transformer-less intelligent power substation (TIPS) system from the condition. However, the currents become uncontrolled if short-circuit occurs in the MV side AFEC due to its internal switching device failure. A wide range of protection schemes is available depending on various factors such as configurations, device ratings, type of faults, etc. Further studies need to explore the better protection schemes capable of protecting from a wide range of faults.

e. Compatibility The current distribution grid was developed extensively for utilizing LFTs. From the transmission and distribution of electric power to solving various issues, the whole power system is entirely compatible with LFT. However, with SST implementation, changes must be made to the grid infrastructure to accommodate its requirements and achieve a smart grid. Changing the whole grid infrastructure is improbable and cost-ineffective; however, implementing the SSTs in a micro-grid is a better approach to slowly replacing the LFTs [109]. In [110], the design and performance of a $3.6 \mathrm{kV}-120 \mathrm{~V} / 10 \mathrm{kVA}$ solid SST lab prototype have been presented for smart grid applications. Emphasizing the need for the work, for facilitating the interfacing of SST with the distribution system, a new micro-grid system is proposed in [76], which integrates SST with zonal dc micro-grid. However, this system is a step forward, but it also highlights many challenges to the system integration of SST with the distribution system. In addition, SST being a new technology, it still lacks the regulatory standards for integration with the grid. Consequently, considering NBR 16149 , it can only inject reactive power when $20 \%$ of active power is injected into the network [111]. Therefore, SST requires regulatory guidelines for its safe integration into the power grid.

f. Isolation Isolation is yet another feature of SST that provides various benefits. Although SST provides galvanic isolation through the high-frequency transformer, 
which is a requirement of smart grids, it involves multiple intermediate stages; these intermediate stages reduce the efficiency [112]. Therefore, the trade-off between galvanic isolation and the high efficiency of the SST needs to be mastered.

\section{Conclusions}

SSTs are a promising step towards sustainable development as the building block of future smart grids. This paper presented a conflate and comprehensive review of the SST, its fundamentals, topologies, application, and future challenges, aiming to provide a brief and straightforward review. The limitations of LFTs and SSTs as their superior and sustainable alternative are the main focus. The SST fundamentals, along with the intermediate conversion stages, are elaborated for deeper insight. The application of components, common control strategies, and recent developments are investigated individually for stage topologies. The applications of the SST utilizing its functionalities as well as replacement of LFTs and presented. The research for application for HVDC transmission and its advancements are investigated. The challenges for the SST implementation are discussed along with research direction for future research.

Author Contributions: Conceptualization, S.K. and K.R.; Formal analysis, S.K., K.R., M.T., S.H. and T.S.B.; Funding acquisition, M.T. and B.A.; Methodology, S.K., K.R., M.T., B.A. and T.S.B.; Project administration, M.T. and B.A.; Resources, S.H.; Supervision, K.R.; Writing-original draft, S.K. and K.R.; Writing-review and editing, M.T., S.H., B.A. and T.S.B. All authors have read and agreed to the published version of the manuscript.

Funding: This research was funded in part by Taif University Researchers Supporting Project Number (TURSP-2020/278), Taif University, Taif, Saudi Arabia, and in part by the collaborative research grant scheme (CRGS) project, Hardware-In-the-Loop (HIL) Lab, Department of Electrical Engineering, Aligarh Muslim University, India having project numbers CRGS/MOHD TARIQ/01 and CRGS/MOHD TARIQ/02.

Institutional Review Board Statement: Not applicable.

Informed Consent Statement: Not applicable.

Data Availability Statement: Not applicable.

Acknowledgments: The authors also acknowledge the technical support provided by the HardwareIn-the-Loop (HIL) Lab, Department of Electrical Engineering, Aligarh Muslim University, India.

Conflicts of Interest: The authors declare no conflict of interest.

\section{References}

1. Harlow, J.H. Electric Power Transformer Engineering; CRC Press: Boca Raton, FL, USA, 2007.

2. Hassan, R.; Radman, G. "Survey on Smart Grid". In Proceedings of the Power Electronic Application Conference, IEEE Southeast Con 2010, Concord, NC, USA, 18-21 March 2010; pp. 210-213.

3. Barker, P.P.; de Mello, R.W. Determining Impact of Distributed Generation on Power Systems: Part 1 Radial Distribution Systems. In Proceedings of the Power Engineering Society Summer Meeting, Seattle, WA, USA, 16-20 July 2000; Volume 3.

4. Ansari, S.; Chandel, A.; Tariq, M. A Comprehensive Review on Power Converters Control and Control Strategies of AC/DC Microgrid. Available online: https:/ /ieeexplore.ieee.org/document/9178771 (accessed on 11 November 2021).

5. Tariq, M.; Maswood, A.I.; Gajanayake, C.J.; Gupta, A.K. A Lithium-ion battery energy storage system using a bidirectional isolated DC-DC converter with current mode control for More Electric Aircraft. In Proceedings of the 2016 IEEE Symposium on Computer Applications \& Industrial Electronics (ISCAIE), Penang, Malaysia, 30-31 May 2016; pp. 149-154. [CrossRef]

6. Elmoudi, A.; Lehtonen, M.; Nordman, H. Effect of Harmonics on Transformers Loss of life. In Proceedings of the IEEE International Symposium on Electrical Insulation, Toronto, ON, Canada, 11-14 June 2006.

7. Beig, A.R.; Ranganathan, V.T. Influence of placement of small space vectors on the performance of PWM techniques for three level inverters. In Proceedings of the IECON'03. 29th Annual Conference of the IEEE Industrial Electronics Society (IEEE Cat. No.03CH37468), Roanoke, VA, USA, 2-6 November 2003; Volume 3, pp. 2764-2770. [CrossRef]

8. Carrasco, J.M.; Franquelo, L.G.; Bialasiewicz, J.T.; Galvan, E.; Guisado, R.C.P.; Prats, M.A.M.; Leon, J.I.; Moreno-Alfonso, N. Power Electronic Systems for the Grid integration of Renewable Energy Sources: A survey. IEEE Trans. Ind. Electron. 2006, 53, 1002-1016. [CrossRef] 
9. Bifaretti, S.; Zanchetta, P.; Watson, A.; Tarisciotti, L.; Clare, J.C. Advanced power electronic conversion and control system for universal and flexible power management. IEEE Trans. Smart Grid. 2011, 2, 231-243. [CrossRef]

10. Zhao, T.F.; Yang, L.Y.; Wang, J.; Huang, A.Q. 270 kVA solid state transformer based on $10 \mathrm{kV}$ SiC power devices. In Proceedings of the 2007 IEEE Electric Ship Technologies Symposium, Arlington, VA, USA, 21-23 May 2007; pp. 145-149.

11. Ronan, E.R.; Sudhoff, S.D.; Glover, S.F.; Galloway, D.L. A power electronic-based distribution transformer. IEEE Trans. Power Deliv. 2002, 17, 537-543. [CrossRef]

12. Tariq, M.; Maswood, A.I.; Gajanayake, C.J.; Ooi, G.H.; Chatterjee, P.; Madishetti, S.; Molligoda, D.A.; Gupta, A.K. Battery integration with more electric aircraft DC distribution network using phase shifted high power bidirectional DC-DC converter. In Proceedings of the 2015 IEEE PES Asia-Pacific Power and Energy Engineering Conference (APPEEC), Brisbane, QLD, Australia, 15-18 November 2015; pp. 1-5. [CrossRef]

13. Wang, G.Y.; Baek, S.; Elliott, J.; Kadavelugu, A.; Wang, F.; She, X.; Dutta, S.; Liu, Y.; Zhao, T.F.; Yao, W.X.; et al. Design and hardware implementation of Gen-I silicon based solid state transformer. In Proceedings of the 2011 Twenty-Sixth Annual IEEE Applied Power Electronics Conference and Exposition (APEC), Fort Worth, TX, USA, 6-11 March 2011; pp. $1344-1349$.

14. Dujic, D.; Zhao, C.; Mester, A.; Steinke, J.K.; Weiss, M.; Schmid, S.L.; Chaudhuri, T.; Stefanutti, P. Power electronic traction transformer: Low voltage prototype. IEEE Trans. Power Electron. 2013, 28, 5522-5534. [CrossRef]

15. Iqbal, M.T.; Tariq, M.; Ahmad, M.K.; Arif, M.S.B. Modeling, analysis and control of buck converter and Z-source converter for photo voltaic emulator. In Proceedings of the 2016 IEEE 1st International Conference on Power Electronics, Intelligent Control and Energy Systems (ICPEICES), Delhi, India, 4-6 July 2016; pp. 1-6. [CrossRef]

16. Huang, A.Q.; Crow, M.L.; Heydt, G.T.; Zheng, J.P.; Dale, S.J. The future renewable electric energy delivery and management system: The energy internet. Proc. IEEE 2011, 99, 133-148. [CrossRef]

17. She, X.; Burgos, R.; Wang, G.Y.; Wang, F.; Huang, A.Q. Review of solid state transformer in the distribution system: From implementation to filed application. In Proceedings of the 2012 IEEE Energy Conversion Congress and Exposition (ECCE), Raleigh, NC, USA, 15-20 September 2012; pp. 4077-4084.

18. She, X.; Huang, A.Q.; Wang, G.Y. 3-D space modulation with voltage balancing capability for a cascaded seven level converter in a solid state transformer. IEEE Trans. Power Electron. 2011, 26, 3778-3789. [CrossRef]

19. Iqbal, M.T.; Maswood, A.I.; Yeo, K.; Tariq, M. Dynamic Model and Analysis of Three phase YD Transformer Based Dual Active Bridge Using Optimised Harmonic Number for Solid State Transformer in Distributed System. In Proceedings of the 2018 IEEE Innovative Smart Grid Technologies-Asia (ISGT Asia), Singapore, 22-25 May 2018; pp. 523-527. [CrossRef]

20. Iqbal, M.; Maswood, A.I.; Khan, M.S.; Tariq, M. Unified harmonic based power calculation for the bidirectional dual active bridge. Electron. Lett. 2018, 54, 1137-1139. [CrossRef]

21. Khan, M.S.U.; Maswood, A.I.; Tafti, H.D.; Roomi, M.M.; Tariq, M. Control of bidirectional DC/DC converter for back to back NPC-based wind turbine system under grid faults. In Proceedings of the 2016 th International Conference on the Development in the in Renewable Energy Technology (ICDRET), Dhaka, Bangladesh, 7-9 January 2016; pp. 1-6. [CrossRef]

22. Kang, M.; Enjeti, P.N.; Pitel, I.J. Analysis and design of electronic transformers for electric power distribution system. IEEE Trans. Power Electron. 1999, 14, 1133-1141. [CrossRef]

23. Khan, S.; Mahmood, A.; Tariq, M.; Zaid, M.; Khan, I.; Rahman, S. Improved Dual Switch Non-Isolated High Gain Boost Converter for DC microgrid Application. In Proceedings of the 2021 IEEE Texas Power and Energy Conference (TPEC), College Station, TX, USA, 2-5 February 2021; pp. 1-6. [CrossRef]

24. Ullah, K.M.S.; Roomi, M.M.; Tariq, M.; Zhao, B. A Unity Power Factor Rectifier based Dynamic Voltage Restorer for Microgrid Applications. In Proceedings of the 2020 IEEE 17th India Council International Conference (INDICON), New Delhi, India, 10-13 December 2020; pp. 1-6. [CrossRef]

25. Dohn, R.L. The Business Case for Microgrids; Siemens AG: Berlin, Germany, 2011.

26. Bosich, D.; Vicenzutti, A.; Pelaschiar, R.; Menis, R.; Sulligoi, G. Toward the future: The MVDC large ship research program. In Proceedings of the 2015 AEIT International Annual Conference (AEIT), Naples, Italy, 14-16 October 2015; pp. 1-6.

27. Doerry, N. Next generation integrated power systems (NGIPS) for the future fleet. In Proceedings of the IEEE Electric Ship Technologies Symposium, Baltimore, MD, USA, 20-22 April 2009; pp. 1-27.

28. Devold, H. Subsea high power long offset electrical power systems. In Proceedings of the US-Norway Oil \& Gas Technology Partnership Conference, Houston, TX, USA, March 2014; 2014. Available online: http:/ /goo.gl/7tWyFc (accessed on 11 November 2021).

29. Dekka, A.; Beig, A.R.; Kanukollu, S.; al Rahis, M.S. Retrofitting of Harmonic Power Filters in Onshore Oil Drilling Rigs: Challenges and Solutions. IEEE Trans. Ind. Appl. 2014, 50, 142-154. [CrossRef]

30. Steiner, M.; Reinold, H. Antriebsschaltungfür ein Schienenfahrzeug. German Patent DE 19827872 A 1, 23 June 1998.

31. Engel, B.; Victor, M.; Bachmann, G.; Falk, A. 15 kV/16.7 Hz energy supply system with medium frequency transformer and $6.5 \mathrm{kV}$ IGBTs in resonant operation. In Proceedings of the 10th European Conference Power Electronics and Applications, Toulouse, France, 2-4 September 2003; pp. 1-10.

32. Kalvelage, G.; Aubin, P.; Coyaud, M. KATIUMTM New power electronic topology that allows reduction of mass and volume and provides a power electronic fault tolerant system. In Proceedings of the PCIM Power Electronics Conference, Nuremberg, Germany, 2005; pp. 760-765. 
33. Taufiq, J. Power electronics technologies for railway vehicles. In Proceedings of the 2007 Power Conversion Conference, Nagoya, Japan, 2-5 April 2007; pp. 1388-1393.

34. Steiner, M.; Reinold, H. Medium frequency topology in railway applications. In Proceedings of the 2007 European Conference on Power Electronics and Applications, Aalborg, Denmark, 2-5 September 2007; pp. 1-10.

35. Zhao, C.; Dujic, D.; Mester, A.; Steinke, J.K.; Weiss, M.; Lewdeni-Schmid, S.; Chaudhuri, T.; Stefanutti, P. Power electronic traction transformer-Medium voltage prototype. IEEE Trans. Ind. Electron. 2014, 61, 3257-3268. [CrossRef]

36. Gerster, C. Smart transformers for traction: Status and challenges. In Proceedings of the ECPE Workshop on Smart Transformers for Traction and Future Grid Applications, Zurich, Switzerland, 4-5 February 2016.

37. Huber, J.E.; Kolar, J.W. Solid-State Transformers: On the Origins and Evolution of Key Concepts. IEEE Ind. Electron. Mag. 2016, 10, 19-28. [CrossRef]

38. Brooks, J.L. Solid state transformer concept development. In Naval Material Command; Civil Eng. Lab., Naval Construction Battalion Center: Port Hueneme, CA, USA, 1980.

39. McMurray, W. Multipurpose power converter circuits. U.S. Patent 3487 289, 30 December 1969.

40. McMurray, W. The thyristor electronic transformer: A power converter using a high-frequency link. IEEE Trans. Ind. Gen. Appl. 1971, IGA-7, 451-457. [CrossRef]

41. McMurray, W. Fast response stepped-wave switching power converter circuit. U.S. Patent 3581212,25 May 1971.

42. McMurray, W. Power converter circuits having a high frequency link. U.S. Patent 3517 300, 23 June 1970.

43. Huang, A.Q. Medium-voltage solid-state transformer. IEEE Ind Electron Mag. 2016, 10, 29-42. [CrossRef]

44. Hengsi, Q.; Kimball, J.W. AC-AC dual active bridge converter for solid state transformer. In Proceedings of the 2009 IEEE Energy Conversion Congress and Exposition, San Jose, CA, USA, 20-24 September 2009; pp. 3039-3044.

45. Qin, H.; Kimball, J.W. Solid-State Transformer Architecture Using AC-AC Dual-Active-Bridge Converter. IEEE Trans. Ind. Electron. 2013, 60, 3720-3730. [CrossRef]

46. Chen, H.; Prasai, A.; Divan, D. Dyna-C: A Minimal Topology for Bidirectional Solid-State Transformers. IEEE Trans. Power Electron. 2017, 32, 995-1005. [CrossRef]

47. Masoum, A.S.; Hashemnia, N.; Abu-Siada, A.; Masoum, M.A.S.; Islam, S.M. Online Transformer Internal Fault Detection Based on Instantaneous Voltage and Current Measurements Considering Impact of Harmonics. IEEE Trans. Power Deliv. 2017, 32, 587-598. [CrossRef]

48. Sabahi, M.; Hosseini, S.H.; Sharifian, M.B.; Goharrizi, A.Y.; Gharehpetian, G.B. Bi-directional power electronic transformer with maximum power-point tracking capability for induction heating applications. IET Power Electron. 2010, 3, 724-731. [CrossRef]

49. Chen, H.; Divan, D. Soft-switching solid state transformer (S4T). IEEE Energy Convers. Congr. Expo. (ECCE) 2017, $33,2933-2947$.

50. Liu, Y.; Liu, Y.; Ge, B.; Abu-Rub, H. Interactive grid interfacing system by matrix-converter based solid state transformer with model predictive control. IEEE Trans. Ind. Inform. 2017, 16, 2533-2541. [CrossRef]

51. Sun, X.; Wang, H.; Qi, L.; Liu, F. Research on Single-Stage High-Frequency-Link SST Topology and Its Optimization Control. IEEE Trans. Power Electron. 2020, 35, 8701-8711. [CrossRef]

52. Cha, H.J.; Enjeti, P.N. A three-phase AC/AC high-frequency link matrix converter for VSCF applications. In Proceedings of the 2003 IEEE 34th Annual Power Electronics Specialist Conference, Acapulco, Mexico, 15-19 June 2003; Volume 1974, pp. 1971-1976.

53. Jin, A.; Li, H.; Li, S. A New Matrix Type Three-Phase Four-Wire Power Electronic Transformer. In Proceedings of the 2006 37th IEEE Power Electronics Specialists Conference, Jeju, Korea, 18-22 June 2006; pp. 1-6.

54. Casarin, J.; Ladoux, P.; Martin, J.; Chauchat, B. AC/DC converter with medium frequency link for railway traction application. Evaluation of semiconductor losses and operating limits. In Proceedings of the SPEEDAM 2010, Pisa, Italy, 14-16 June 2010; pp. 1706-1711.

55. Sabahi, M.; Hosseini, S.H.; Sharifian, M.B.; Goharrizi, A.Y.; Gharehpetian, G.B. Zero-voltage switching bi-directional power electronic transformer. IET Power Electron. 2010, 3, 818-828. [CrossRef]

56. Yun, H.J.; Kim, H.S.; Ryu, M.H.; Baek, J.W.; Kim, H.J. A simple and practical voltage balance method for a solid-state transformer using cascaded H-bridge converters. In Proceedings of the 9th International Conference on Power Electronics (ICPE), Seoul, Korea, 1-5 June 2015; pp. 2415-2420.

57. Bhaskar, R.; Agarwal, V. Dual pid loop controller for HF link inverter in two-stage SST. In Proceedings of the 2016 IEEE 7th Power India International Conference (PIICON), Bikaner, India, 25-27 November 2016; pp. 1-4. [CrossRef]

58. Madhusoodhanan, S.; Tripathi, A.; Patel, D.; Mainali, K.; Kadavelugu, A.; Hazra, S.; Bhattacharya, S.; Hatua, K. Solid-State Transformer and MV Grid Tie Applications Enabled by $15 \mathrm{kV}$ SiC IGBTs and $10 \mathrm{kV}$ SiC MOSFETs Based Multi-level Converters. IEEE Trans. Ind. Appl. 2015, 51, 3343-3360. [CrossRef]

59. Madhusoodhanan, S.; Mainali, K.; Tripathi, A.; Patel, D.; Kadavelugu, A.; Bhattacharya, S.; Hatua, K. Harmonic Analysis and Controller Design of $15 \mathrm{kV}$ SiC IGBT Based Medium Voltage Grid Connected Three-Phase Three Level NPC Converter. IEEE Trans. Power Electron. 2016, 32, 3355-3369. [CrossRef]

60. Mostafa, M.A.; Abdou, A.F.; Abd El-Gawad, A.F.; El-Kholy, E.E. SBO based selective harmonic elimination for nine levels asymmetrical cascaded H-bridge multi-level inverter. Aust. J. Electr. Electron. Eng. 2018, 15, 131-143. [CrossRef]

61. Mostafa, M.A.; Abdou, A.F.; El-Gawad, A.F.A.; El-kholy, E.E. Comparison of multi-carrier and SHE-PWM for a nine levels cascaded $\mathrm{H}$ bridge inverter. In Proceedings of the 2017 Nineteenth International Middle East Power Systems Conference (MEPCON), Cairo, Egypt, 19-21 December 2017; pp. 1483-1491. 
62. Falcones, S.; Mao, X.; Ayyanar, R. Topology comparison for Solid State Transformer implementation. In Proceedings of the IEEE PES General Meeting, Minneapolis, MN, USA, 25-29 July 2010; pp. 1-8.

63. Qin, H.; Kimball, J.W. A comparative efficiency study of silicon-based solid state transformers. In Proceedings of the 2010 IEEE Energy Conversion Congress and Exposition, Atlanta, GA, USA, 12-16 September 2010; pp. 1458-1463.

64. Zhang, J.; Wang, Z.; Shao, S. A three-phase modular multilevel DC-DC converter for power electronic transformer applications. IEEE J. Emerg. Sel. Top. Power Electron. 2017, 5, 140-150. [CrossRef]

65. Zhang, C.; Wang, H.; Peng, J.; Yu, J. Control of Three-Stage AC-AC Solid State Transformer for Power Exchange Between Grids. In Proceedings of the 2019 IEEE PES Asia-Pacific Power and Energy Engineering Conference (APPEEC), Macao, China, 1-4 December 2019; pp. 1-5. [CrossRef]

66. Abu-Siada, A.; Budiri, J.; Abdou, A.F. Solid State Transformers Topologies, Controllers, and Applications: State-of-the-Art Literature Review. Electronics 2018, 7, 298. [CrossRef]

67. Drabek, P.; Peroutka, Z.; Pittermann, M.; Cedl, M. New configuration of traction converter with medium frequency transformer using matrix converters. IEEE Trans. Ind. Electron. 2011, 58, 5041-5048. [CrossRef]

68. Komrska, T.; Peroutka, Z. Main traction converter with medium frequency transformer: Control of converters around MF transformer. In Proceedings of the 2008 International Symposium on Power Electronics, Electrical Drives, Automation and Motion, Ischia, Italy, 11-13 June 2008; pp. 1194-1198.

69. Hugo, N.; Stefanutti, P.; Pellerin, M.; Akdag, A. Power electronic traction transformer. In Proceedings of the EPE, Birmingham, UK, 5 October 2007; pp. 1-10.

70. Carpita, M.; Marchesoni, M.; Pellerin, M.; Moser, D. Multi-level converter for traction applications: Small-scale prototype test results. IEEE Trans. Ind. Electron. 2008, 55, 2203-2212. [CrossRef]

71. Glinka, M.; Marquardt, R. A new AC/AC multi-level converter family. IEEE Trans. Ind. Electron. 2005, 52, 662-669. [CrossRef]

72. Claessens, M.; Dujic, D.; Steinke, J.K.; Stefanutti, P.; Vetterli, C. Traction transformation: A power electronic traction transformer (PETT). ABB Rev. 2012, 3, 1-3.

73. Zhang, J.; Liu, J.; Zhong, S.; Yang, J.; Zhao, N.; Zheng, T.Q. A Power Electronic Traction Transformer Configuration with Low-Voltage IGBTs for Onboard Traction Application. IEEE Trans. Power Electron. 2019, 34, 8453-8467. [CrossRef]

74. Pacheco, J.D.O.; Honório, D.D.A.; Oliveira, D.D.S. An AC-DC Isolated MMC-Based Structure Suitable for MV SST Traction Applications. IEEE Access 2019, 7, 106395-106406. [CrossRef]

75. Frutos, P.; Briz, F.; Sánchez, A.; Guerrero, J.M. Quad-Active-Bridge as the basic cell of a MMC Based SST for DER and DESS Integration. In Proceedings of the 2019 IEEE 28th International Symposium on Industrial Electronics (ISIE), Vancouver, BC, Canada, 12-14 June 2019; pp. 2349-2355. [CrossRef]

76. She, X.; Huang, A.Q.; Lukic, S.; Baran, M. On integration of solid state transformer with zonal DC microgrid. IEEE Trans. Smart Grid. 2012, 3, 975-985. [CrossRef]

77. She, X.; Lukic, S.; Huang, A.Q.; Bhattacharya, S.; Baran, M. Performance evaluation of solid state transformer based microgrid in FREEDM systems. In Proceedings of the 2011 Twenty-Sixth Annual IEEE Applied Power Electronics Conference and Exposition (APEC), Fort Worth, TX, USA, 6-11 March 2011; pp. 182-188.

78. Madhusoodhanan, S.; Tripathi, A.; Mainali, K.; Patel, D.; Kadavelugu, A.; Bhattacharya, S. Distributed Energy Storage Device integration with three phase distribution grid using a Transformerless Intelligent Power Substation. In Proceedings of the 2015 IEEE Applied Power Electronics Conference and Exposition (APEC), Charlotte, NC, USA, 15-19 March 2015; pp. 670-677. [CrossRef]

79. Tudorache, T.; Marinescu, A.; Dumbrava, I. On-road Charging System Demonstrator for EVs. In Proceedings of the 2019 Electric Vehicles International Conference (EV), Bucharest, Romania, 3-4 October 2019; pp. 1-4. [CrossRef]

80. Pool-Mazun, E.I.; Sandoval, J.J.; Enjeti, P.N.; Pitel, I.J. An Integrated Solid State Transformer (I-SST) with High-Frequency Isolation for EV Fast-Charging Applications. IEEE J. Emerg. Sel. Top. Ind. Electron. 2020, 1, 46-56. [CrossRef]

81. Borgaonkar, A. Solid State Transformers: A Review of Technology and Applications. Indian Inst. Technol. 2015. [CrossRef]

82. Kadandani, N.B.; Dahidah, M.; Ethni, S.; Yu, J. Solid state transformer: An overview of circuit configurations and applications. In Proceedings of the 15th IET International Conference on AC and DC Power Transmission (ACDC 2019), Coventry, UK, 5-7 February 2019; pp. 1-6. [CrossRef]

83. Shen, Z.; Wang, Z.; Baran, M.E. Optimal volt/var control strategy for distribution system with multiple voltage regulating devices. In Proceedings of the PES T\&D 2012, Orlando, FL, USA, 7-10 May 2012; pp. 1-7. [CrossRef]

84. Verma, N.; Singh, N.; Yadav, S.; Gupta, S. Reactive Power Compensation of Solid State Transformer for WECS. In Proceedings of the 2018 2nd International Conference on Electronics, Materials Engineering \& Nano-Technology (IEMENTech), Kolkata, India, 4-5 May 2018; pp. 1-6. [CrossRef]

85. She, X.; Huang, A.Q.; Wang, F.; Burgos, R. Wind Energy System with Integrated Functions of Active Power Transfer, Reactive Power Compensation, and Voltage Conversion. IEEE Trans. Ind. Electron. 2013, 60, 4512-4524. [CrossRef]

86. Gorla, N.B.Y.; Kolluri, S.; Chauhan, P.J.; Panda, S.K. A fault tolerant control approach for a three-stage cascaded multi-level solid state transformer. In Proceedings of the 2017 IEEE 18th Workshop on Control and Modeling for Power Electronics (COMPEL), Stanford, CA, USA, 9-12 July 2017; pp. 1-6. [CrossRef] 
87. Vodyakho, O.; Steurer, M.; Edrington, C.; Karady, G.; Bhattacharya, S. Instantiation of solid state fault isolation devices for future power electronic based distribution systems. In Proceedings of the IEEE PES General Meeting, Minneapolis, MN, USA, 25-29 July 2010; pp. 1-8. [CrossRef]

88. Kikuchi, J.; Lipo, T.A. Three-phase PWM boost-buck rectifiers with power-regenerating capability. IEEE Trans. Ind. Appl. 2002, 38, 1361-1369. [CrossRef]

89. Maharjan, M.; Tamrakar, U.; Bajagain, S.; Hansen, T.M.; Tonkoski, R. A steady-state equivalent model of solid state transformers for voltage regulation studies. In Proceedings of the 2017 IEEE Power \& Energy Society General Meeting, Chicago, IL, USA, 16-20 July 2017; pp. 1-5. [CrossRef]

90. Liu, X.; Liu, Y.; Liu, J.; Zhang, X. Coordinating voltage regulation for an AC-DC hybrid distribution network with multiple SSTs J. Eng. 2019, 2019, 1368-1372. [CrossRef]

91. Jianyang, Y.; Khan, M.Q.; Yanwen, Z.; Khan, M.M.; Ali, M. HVDC bidirectional power flow using solid state transformer. In Proceedings of the 2017 International Conference on Circuits, Devices and Systems (ICCDS), Chengdu, China, 5-8 September 2017; pp. 110-114. [CrossRef]

92. Zhao, H.; Yang, B. A Novel Conception for HVDC Transmission Capacity Expansion and Its Control Strategy. In Proceedings of the 2018 IEEE International Power Electronics and Application Conference and Exposition (PEAC), Shenzhen, China, 4-7 November 2018; pp. 1-6. [CrossRef]

93. Kimura, N.; Morizane, T.; Iyoda, I.; Nakao, K.; Yokoyama, T. Application of Solid-State Transformer for HVDC Transmission from Offshore Windfarm. In Proceedings of the 2018 7th International Conference on Renewable Energy Research and Applications (ICRERA), Paris, France, 14-17 October 2018; pp. 902-907. [CrossRef]

94. Zapico, A.; Lopez, M.; Rodriguez, A.; Briz, F. Fault tolerant cell design for MMC-based multiport power converters. In Proceedings of the 2016 IEEE Energy Conversion Congress and Exposition (ECCE), Milwaukee, WI, USA, 18-22 September 2016; pp. 1-8. [CrossRef]

95. She, X.; Huang, A.Q.; Burgos, R. Review of Solid-State Transformer Technologies and Their Application in Power Distribution Systems. IEEE J. Emerg. Sel. Top. Power Electron. 2013, 1, 186-198. [CrossRef]

96. Gadgil, K.S. Solid State Transformers. Int. J. Adv. Res. Innov. Ideas Educ. 2016, 2, 320-324.

97. She, X.; Huang, A.Q.; Ni, X. A cost effective power sharing strategy for a cascaded multilevel converter based solid state transformer. In Proceedings of the 2013 IEEE Energy Conversion Congress and Exposition, Denver, CO, USA, 15-19 September 2013; pp. 372-379.

98. Federal Register, 10 CFR Part 431, Energy Conversation Program for Commercial Equipment, Distribution transformers Energy Conversation Standards; Final Rule (U.S. Department of Energy). Prepared by the Office of the Federal Register, National Archives and Records Administration (12 October 2007). Available online: https:/ / www.federalregister.gov / documents/2007/10/12/E7 -19582/energy-conservation-program-for-commercial-equipment-distribution-transformers-energy-conservation (accessed on 11 November 2021).

99. Besselmann, T.; Mester, A.; Dujic, D. Power Electronic Traction Transformer: Efficiency Improvements under Light-Load Conditions. IEEE Trans. Power Electron. 2014, 29, 3971-3981. [CrossRef]

100. Zhang, L.; Zhao, Z.; Qin, J. Efficiency optimization design of DC-DC solid state transformer based on modular multilevel converters. In Proceedings of the 2017 IEEE Energy Conversion Congress and Exposition (ECCE), Cincinnati, OH, USA, 1-5 October 2017; pp. 3508-3513. [CrossRef]

101. EPRI (2004) Feasibility Study for the Development of High-Voltage, Low-Current Power Semiconductor Devices; EPRI Report 1001698; 2004; Available online: https:/ / preview.epri.com/research/products/000000000001009516 (accessed on 11 November 2021).

102. EPRI (2004) Development of a New Multi-Level Converter-Based Intelligent Universal Transformer: Design Analysis; EPRI Report 1002159; 2004; Available online: https:/ / preview.epri.com/research/products/000000000001002159 (accessed on 11 November 2021).

103. Wang, K.; Lei, Q.; Liu, C. Methodology of reliability and power density analysis of SST topologies. In Proceedings of the 2017 IEEE Applied Power Electronics Conference and Exposition (APEC), Tampa, FL, USA, 26-30 March 2017; pp. 1851-1856. [CrossRef]

104. Guillod, T.; Krismer, F.; Kolar, J.W. Protection of mv converters in the grid: The case of mv/lv solid-state transformers. IEEE J. Emerg. Sel. Top. Power Electron. 2017, 5, 393-408. [CrossRef]

105. Singh, U.; Baran, M.E. Protection of smart distribution systems with distributed energy resources and solid state transformers. In Proceedings of the 2017 IEEE Power Energy Society General Meeting, Chicago, IL, USA, 16-20 July 2017; pp. 1-5.

106. Tatcho, P.; Li, H.; Jiang, Y.; Qi, L. A Novel Hierarchical Section Protection Based on the Solid State Transformer for the Future Renewable Electric Energy Delivery and Management (FREEDM) System. IEEE Trans. Smart Grid. 2013, 4, 1096-1104. [CrossRef]

107. Jakka, V.N.; Acharya, S.; Anurag, A.; Prabowo, Y.; Kumar, A.; Parashar, S.; Bhattacharya, S. Protection Design Considerations of a $10 \mathrm{kV}$ SiC MOSFET Enabled Mobile Utilities Support Equipment Based Solid State Transformer (MUSE-SST). In Proceedings of the IECON 2018 - 44th Annual Conference of the IEEE Industrial Electronics Society, Washington, DC, USA, 21-23 October 2018; pp. 5559-5565. [CrossRef]

108. Madhusoodhanan, S.; Patel, D.; Bhattacharya, S.; Carr, J.A.; Wang, Z. Protection of a transformerless intelligent power substation. In Proceedings of the 2013 4th IEEE International Symposium on Power Electronics for Distributed Generation Systems (PEDG), Rogers, AR, USA, 8-11 July 2013; pp. 1-8. 
109. Bala, S.; Das, D.; Aeloiza, E.; Maitra, A.; Bajagopalan, S. Hybrid transformer: Concept development and filed demonstration. In Proceedings of the 2012 IEEE Energy Conversion Congress and Exposition (ECCE), Raleigh, NC, USA, 15-20 September 2012; pp. 4061-4068.

110. She, X.; Yu, X.; Wang, F.; Huang, A.Q. Design and demonstration of a 3.6 kV-120 V/10 KVA solid state transformer for smart grid application. In Proceedings of the 2014 IEEE Applied Power Electronics Conference and Exposition-APEC 2014, Fort Worth, TX, USA, 16-20 March 2014; pp. 3429-3436. [CrossRef]

111. Londero, R.P.; Mello, A.P.C.d.; da Silva, G.S. Comparison between conventional and solid state transformers in smart distribution grids. In Proceedings of the 2019 IEEE PES Innovative Smart Grid Technologies Conference-Latin America (ISGT Latin America), Gramado, Brazil, 15-18 September 2019; pp. 1-6. [CrossRef]

112. Fan, H.; Li, H. High-Frequency Transformer Isolated Bidirectional DC-DC Converter Modules with High Efficiency over Wide Load Range for 20 kVA Solid-State Transformer. IEEE Trans. Power Electron. 2011, 26, 3599-3608. [CrossRef] 